\title{
Incidence of and risk factors for postoperative delirium in older adult patients undergoing noncardiac surgery: a prospective study
}

Arissara lamaroon ${ }^{1}$, Titima Wongviriyawong ${ }^{2}$, Patumporn Sura-arunsumrit ${ }^{2}$, Nattikan Wiwatnodom', Nichakarn Rewuri ${ }^{1}$ and Onuma Chaiwat ${ }^{1, *^{*}}$ (i)

\begin{abstract}
Background: To identify the incidence of, risk factors for, and outcomes associated with postoperative delirium (POD) in older adult patients who underwent noncardiac surgery.

Methods: This prospective study recruited patients aged $\geq 60$ years who were scheduled to undergo noncardiac surgery at Siriraj Hospital (Bangkok, Thailand). Functional and cognitive statuses were assessed preoperatively using Barthel Index (BI) and the modified Informant Questionnaire on Cognitive Decline in the Elderly, respectively. POD was diagnosed based on the Diagnostic and Statistical Manual of Mental Disorders Fifth Edition criteria. Incidence of POD was reported. Univariate and multivariate analyses were used to identify risk factors for POD.

Results: Of the 249 included patients, 29 (11.6\%) developed POD. Most patients (61.3\%) developed delirium on postoperative day 1 . Univariate analysis showed age $\geq 75$ years, Bl score $\leq 70$, pre-existing dementia, preoperative use of opioid or benzodiazepine, preoperative infection, and hematocrit $<30 \%$ to be significantly associated with POD. Multivariate logistic analysis revealed pre-existing dementia (adjusted risk ratio [RR]: 3.95, 95\% confidence interval [CI]: 1.91-8.17; $p<0.001$ ) and age $\geq 75$ years (adjusted RR: $2.54,95 \%$ Cl: $1.11-5.80 ; p=0.027$ ) to be independent risk factors for POD. Median length of hospital stay was 10 (range: $3-36$ ) days for patients with POD versus 6 (range: $2-$ 76) days for those without delirium $(p<0.001)$.

Conclusions: POD remains a common surgical complication, with an incidence of $11.6 \%$. Patients with pre-existing dementia and age $\geq 75$ years are the most vulnerable high-risk group. A multidisciplinary team consisting of anesthesiologists and geriatricians should implement perioperative care to prevent and manage POD.
\end{abstract}

Keywords: Collaborative approach, Incidence, Risk factors, Postoperative delirium, Older adult patients, Noncardiac surgery

\section{Background}

Delirium is a common postoperative complication that occurs in 5 to $52 \%$ of older adult patients after noncardiac surgery $[1,2]$. Delirium is characterized by disturbance in attention, awareness, and cognition that develops acutely and fluctuates frequently throughout the course of the condition [3]. POD adversely impacts patient quality of

\footnotetext{
* Correspondence: onuma.cha@mahidol.ac.th

${ }^{1}$ Department of Anesthesiology, Faculty of Medicine Siriraj Hospital, Mahidol University, Bangkok 10700, Thailand

${ }^{3}$ Integrated Perioperative Geriatric Excellent Research Center, Faculty of Medicine, Siriraj Hospital, Mahidol University, Bangkok 10700, Thailand Full list of author information is available at the end of the article
}

life, and increases the burden on the patient's family. Delirium has been associated with adverse outcomes, such as functional decline $[4,5]$, dementia or cognitive impairment [6, 7], increased hospital length of stay [8, 9], increased mortality [7-9], institutionalization [7, 8], and increased healthcare costs [10].

As the population of older adults increases, so too with the number of older adult patients that present for anesthesia and surgery. The development of delirium following surgery has some significant potential effects on patient outcomes; however, POD is often underdiagnosed. Some studies reported that more than $50 \%$ of

(c) The Author(s). 2020 Open Access This article is distributed under the terms of the Creative Commons Attribution 4.0 International License (http://creativecommons.org/licenses/by/4.0/), which permits unrestricted use, distribution, and reproduction in any medium, provided you give appropriate credit to the original author(s) and the source, provide a link to the Creative Commons license, and indicate if changes were made. The Creative Commons Public Domain Dedication waiver (http://creativecommons.org/publicdomain/zero/1.0/) applies to the data made available in this article, unless otherwise stated. 
patients with delirium were undiagnosed by medical teams [11-13]. Moreover, it is sometimes difficult to differentiate delirium, especially hypoactive delirium, from the residual effects of anesthesia during the early postoperative period [14]. Delirium has multifactorial causes and complex pathophysiological mechanisms. Clinical studies of incidence and risk factors associated with POD may provide additional useful clues to the optimal perioperative care of older adult surgical patients at risk for delirium. Risk identification may also help clinicians provide patient-specific management during the perioperative period.

The gold standard diagnostic criteria for delirium is the Diagnostic and Statistical Manual of Mental Disorders Fifth Edition (DSM-5) from the American Psychiatric Association [3]. Definitive delirium diagnosis should be performed by a trained and experienced physician, such as a geriatrician or psychiatrist. A standardized diagnostic tool used by a trained and experienced physician may help to maximize the detection of POD. Traditionally, geriatric consultation is usually activated once the patient develops delirium after an operation. Proactive geriatric consultation together with the careful anesthesia techniques for surgical patients who have risk for delirium may reduce the incidence of POD and its associated adverse outcomes during the perioperative period. A collaborative approach between geriatricians and anesthesiologists may also improve the quality of patient care and patient outcomes. Before a program with these objectives can be developed and implemented, the scope of the problem and factors that significantly associate with POD must be identified.

Accordingly, the aim of this study was to enlist anesthesiologists and geriatricians to collaboratively investigate the incidence of, risk factors for, and outcomes associated with POD among older adult patients who underwent noncardiac surgery.

\section{Methods}

After receiving Siriraj Institutional Review Board (COA no. Si 718/2015) approval, a prospective cohort study was conducted at a large university-based national tertiary referral center during the March 2017 to December 2017 study period. Patients aged 60 years or older who were scheduled to undergo noncardiac surgery were eligible for inclusion. Patients were excluded if they refused to participate in the study or required postoperative intensive care unit admission. The protocol for this study followed all of the guidelines outlined in the Declaration of Helsinki and all of its later amendments. Written informed consent was obtained from all study participants.

Preoperatively, all patients were assessed for functional and cognitive status by the clinical researcher or a trained research assistant. Functional status was assessed using the Barthel Index of Activities of Daily Living [15].
The Barthel Index (BI) consists of 10 items that assess self-care abilities, including feeding, grooming, bathing, dressing, toilet use, bowel and bladder control, mobility, stair climbing, and transferring from bed to chair. Scoring ranges from 0 (totally dependent) to 100 (fully independent). The rating was classified as $\leq 70$ or $>70$. The information was obtained from an observation of patient performance or a caregiver interview.

Cognitive status was measured using the modified Informant Questionnaire on Cognitive Decline in the Elderly (IQCODE), which is based on information elicited from a close relative or caregiver of each patient. The modified IQCODE for detection of dementia in Thai older adults (90\% sensitivity, $95 \%$ specificity, $94 \%$ positive predictive value, and $90 \%$ negative predictive value) consists of 32 items designed to assess cognitive changes over the previous 10 years [16]. Scoring ranges from 1 (much improved) to 5 (much worse), and total scores were divided by the number of items (32) to give an average score of 1-5, with an optimal cutoff score of 3.42. Accordingly, patients with a modified IQCODE score greater than or equal to 3.42 were considered to have some degree of dementia [16]. Patients with a pre-existing diagnosis of dementia were also obviously similarly classified.

POD was diagnosed by one of three geriatricians based on the DSM-5 criteria [3]. All three geriatricians have had experience in caring for older adult patients with delirium and dementia for an experience duration ranging from 5 to 15 years. To enhance agreement among geriatricians relative to delirium diagnosis, a DSM-5 interrater reliability among these three geriatricians was measured, and a level of agreement ranging from 90 to $100 \%$ was obtained. Daily patient assessment for POD was performed during the daytime for 7 consecutive days after surgery. The occurrence of POD and delirium onset time was documented.

The surgical procedures and anesthetic techniques were carried out with no specific intervention from the research team. Patient demographic data, comorbidities, type and duration of surgery, anesthesia technique, intraoperative hypotension, intraoperative hypoxemia, and length of hospital stay were recorded. Intraoperative hypotension was defined as either systolic blood pressure less than $90 \mathrm{mmHg}$ for more than $5 \mathrm{~min}$ or the use of vasopressor to treat hypotension [17]. Intraoperative hypoxemia was defined as oxygen saturation, measured by pulse oximeter, of below $90 \%$ for any duration [18].

Medications used within 3 months before surgery were also recorded, including opioids, benzodiazepines, statins, anticonvulsants, and psychotropic drugs (antipsychotics, antidepressants, and antianxiety drugs were grouped together as psychotropic drugs). Preoperative laboratory values, including hematocrit (Hct), sodium, and ratio of blood urea nitrogen to creatinine (BUN/Cr 
ratio), were measured and recorded. Maximum pain scores on the first postoperative day were determined using a numeric rating scale (NRS) on a 10-point scale. Pain intensity was classified as mild (NRS $=1-3$ ), moderate $(\mathrm{NRS}=4-7)$, or severe $(\mathrm{NRS}=8-10)$ pain.

\section{Statistical analysis}

The sample size was estimated based on multiple logistic regression analysis [19]. Based on literature review, the risk factors for POD were approximately 10 variables [2] and the number of patients with delirium should be 5 to 10 times of risk factors. From the previous study [8], the incidence of POD was $44 \%$ among patients undergoing noncardiac surgery. The sample size was calculated and a minimum sample size of 227 patients was required. To compensate for a possible $10 \%$ dropout rate for any reason, a minimum total study population of 250 patients was required.

All statistical analyses were performed using PASW Statistics version 18.0 (SPSS, Inc., Chicago, IL, USA) and MedCalc Statistic Software version 17.6 (MedCalc Software BVBA, Ostend, Belgium). Continuous data are presented as mean \pm standard deviation (SD) for normally distributed data, and as median and interquartile range for non-normally distributed data. Categorical data are presented as frequency and percentage. All variables in patients without POD versus those with POD were analyzed by univariate logistic regression analysis using chi-square test, Fisher's exact test, independent $t$-test, or Mann-Whitney U test, as appropriate. Seven risk factors with univariable $p$-value less than 0.05 including preexisting dementia, age $\geq 75$ years, hematocrit $<30 \%$, preoperative opioid use, preoperative benzodiazepine use, preoperative infection, and Barthel index score $\leq 70$ were entered into multiple regression model. Risk ratios and adjusted risk ratios with their respective 95\% confidence intervals were reported. A $p$-value less than 0.05 was considered to be statistically significant for all tests. Receiver operating characteristic (ROC) curve analysis was performed to identify the optimal cutoff age for developing delirium. The results of that analysis are reported as Youden's index, sensitivity, specificity, positive predictive value, negative predictive value, positive likelihood ratio, negative likelihood ratio, and area under curve.

\section{Results}

During the study period, a total of 269 patients were assessed for eligibility. Of those, 20 patients were excluded for the reasons showed in Fig. 1. The remaining 249 patients were included and completed the study. The demographic and clinical data of patients are summarized in Table 1. Perioperative data is described in Table 2.

Using DSM-5 criteria, 29 of 249 patients developed delirium, for an incidence of $11.6 \%$. The majority of patients (61.3\%) developed delirium on postoperative day 1, followed by $16.1 \%$ on day $2,12.9 \%$ on day $3,6.5 \%$ on day 5 , and $3.2 \%$ on day 6 . As shown in Table 1, patients with delirium were significantly older $(p<0.001)$, had a greater prevalence of pre-existing dementia $(p<0.001)$, had a lower Barthel Index score $(p=0.001)$, and had a higher rate of preoperative opioid $(p=0.001)$ or benzodiazepine $(p=0.022)$ relative to those patients without delirium. In

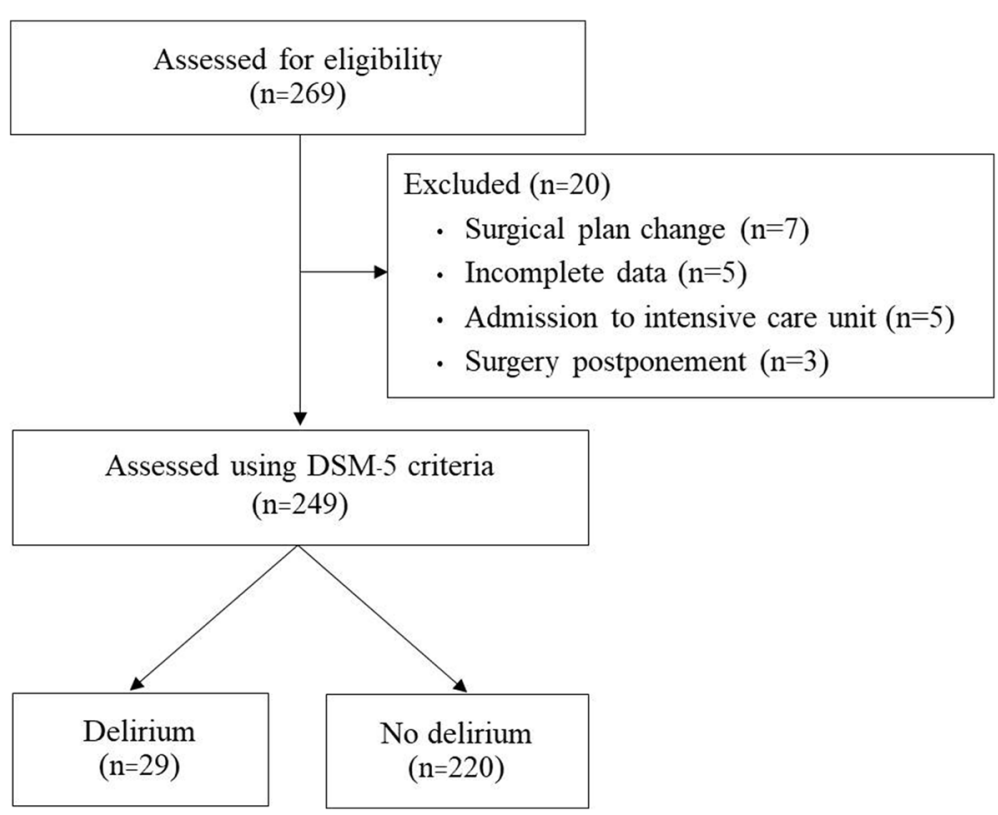

Fig. 1 Flow diagram of patient enrollment 
Table 1 Demographic and clinical data of patients without and with delirium

\begin{tabular}{|c|c|c|c|c|}
\hline Variables & $\begin{array}{l}\text { Total } \\
(n=249)\end{array}$ & $\begin{array}{l}\text { No delirium } \\
(n=220 ; 88.4 \%)\end{array}$ & $\begin{array}{l}\text { Delirium } \\
(n=29 ; 11.6 \%)\end{array}$ & $p$-value \\
\hline Age (years), mean $\pm S D$ & $75.1 \pm 7.9$ & $74.4 \pm 6.9$ & $80.7 \pm 6.6$ & $<0.001$ \\
\hline Age $\geq 75$ years, $n(\%)$ & $125(50.2)$ & $102(46.4)$ & $23(79.3)$ & 0.001 \\
\hline Female gender, n (\%) & $154(61.8)$ & $137(62.3)$ & $17(58.6)$ & 0.839 \\
\hline ASA physical status, n (\%) & & & & 0.545 \\
\hline$\|$ & $152(61.0)$ & $136(61.8)$ & $16(52.5)$ & \\
\hline III & $97(39.0)$ & $84(38.2)$ & $13(44.8)$ & \\
\hline Barthel Index scores $\leq 70, \mathrm{n}(\%)$ & $51(20.5)$ & $38(17.3)$ & $13(44.8)$ & 0.001 \\
\hline Alcohol $\geq 2$ drinks daily, $n$ (\%) & $83(33.3)$ & $73(33.2)$ & $10(34.5)$ & 1.000 \\
\hline Smoking $\geq 30$ pack year, n (\%) & $68(27.3)$ & $61(27.7)$ & $7(24.1)$ & 0.826 \\
\hline \multicolumn{5}{|l|}{ Comorbidities, n (\%) } \\
\hline Diabetes mellitus & $84(33.7)$ & $78(35.5)$ & $6(20.7)$ & 0.144 \\
\hline Hypertension & $184(73.9)$ & $165(75.0)$ & $19(65.5)$ & 0.368 \\
\hline Heart disease & $43(17.3)$ & $36(16.4)$ & $7(24.1)$ & 0.433 \\
\hline Stroke or TIA & $13(5.2)$ & $12(5.5)$ & $1(3.4)$ & 1.000 \\
\hline ESRD or CKD & $54(21.7)$ & $48(21.8)$ & $6(20.7)$ & 1.000 \\
\hline Cirrhosis & $5(2.0)$ & $5(2.3)$ & $0(0.0)$ & 1.000 \\
\hline Cancer & $55(22.1)$ & $45(20.5)$ & $10(34.5)$ & 0.098 \\
\hline Dementia & $42(16.9)$ & $26(11.8)$ & $16(55.2)$ & $<0.001$ \\
\hline Preoperative infection & $24(9.6)$ & $18(8.2)$ & $6(20.7)$ & 0.044 \\
\hline \multicolumn{5}{|l|}{ Preoperative medications, n (\%) } \\
\hline Opioids & $36(14.5)$ & $25(11.4)$ & $11(37.9)$ & 0.001 \\
\hline Benzodiazepines & $37(14.9)$ & $28(12.7)$ & $9(31.0)$ & 0.022 \\
\hline Psychotropics & $14(5.6)$ & $11(5.0)$ & $3(10.33)$ & 0.214 \\
\hline Anticonvulsants & $19(7.6)$ & $14(6.4)$ & $5(16.1)$ & 0.054 \\
\hline Statins & 136 (54.6) & $124(56.4)$ & $12(41.4)$ & 0.165 \\
\hline
\end{tabular}

A $p$-value $<0.05$ indicates statistical significance

Abbreviations: SD standard deviation, ASA American Society of Anesthesiologists, TIA transient ischemic attack, ESRD end-stage renal disease, CKD chronic kidney disease

addition, among patients with delirium versus those without delirium, hematocrit less than $30 \%$ (27.6\% vs. $12.3 \%$, respectively; $p=0.042)$ and preoperative infection $(20.7 \%$ vs. $8.2 \%$, respectively; $p=0.044$ ) were significantly associated with the development of delirium. Median length of hospital stay was 10 (range: 3-36) days for patients with delirium versus 6 (range: $2-76$ ) days for those without delirium $(p<0.001)$. In multivariate analysis, only preexisting dementia (adjusted risk ratio [RR]: 3.95 , 95\% confidence interval [CI]: $1.91-8.17 ; p<0.001)$ and age $\geq 75$ years (adjusted RR: 2.54, 95\% CI: $1.11-5.80 ; p=0.027$ ) remained significantly associated with POD in patients undergoing noncardiac surgery (Table 3). The ROC curve, with its area under curve of 0.74 (95\% CI: 0.65-0.83), is shown in Fig. 2. The optimal cutoff age for developing delirium was age $\geq 75$ years. The sensitivity, specificity, positive predictive value, negative predictive value and Youden's index for optimal cutoff age was 79.3, 53.6\%, 18.4, 95.2, and 0.34, respectively (Table 4).

\section{Discussion}

Based on DSM-5 criteria, this prospective cohort study found an $11.6 \%$ incidence of postoperative delirium among the older adult patients admitted to the surgical ward after noncardiac surgery. Pre-existing dementia and age 75 years or older were the independent risk factors for POD in these patients. In terms of outcome, patients who developed delirium had longer hospital stay than those without delirium. There was no in-hospital mortality in this study.

The $11.6 \%$ incidence of POD in the present study was similar to the $13.2 \%$ incidence reported in a previous study [9]. This is comparable with the $18.4 \%$ pooled incidence of POD reported by a systematic review of 41 studies [20]. In contrast, a high incidence rate of POD in the surgical intensive care unit has been reported to range from 24.4 to $44 \%[8,21]$. This reflects the fact that the reported incidence of POD varies from study to study depending on the patient population, timing of 
Table 2 Perioperative data of patients without and with delirium

\begin{tabular}{|c|c|c|c|c|}
\hline Variables & $\begin{array}{l}\text { Total } \\
(n=249)\end{array}$ & $\begin{array}{l}\text { No delirium } \\
(n=220)\end{array}$ & $\begin{array}{l}\text { Delirium } \\
(n=29)\end{array}$ & $p$-value \\
\hline Type of surgery, n (\%) & & & & 0.606 \\
\hline Vascular & $10(4.0)$ & $8(3.6)$ & $2(6.9)$ & \\
\hline Urological & $26(10.4)$ & $24(10.9)$ & $2(6.9)$ & \\
\hline General & $94(37.8)$ & 85 (38.6) & $9(31.0)$ & \\
\hline Orthopedic & $119(47.8)$ & $103(46.8)$ & $16(55.2)$ & \\
\hline Urgent surgery, n (\%) & $38(15.3)$ & $30(13.6)$ & $8(27.6)$ & 0.058 \\
\hline Operative time (min), mean \pm SD & $115.3 \pm 70.0$ & $115.3 \pm 68.9$ & $115.3 \pm 79.0$ & 0.997 \\
\hline Type of anesthesia, n (\%) & & & & 0.659 \\
\hline General & $142(57.0)$ & $126(57.3)$ & $16(55.2)$ & \\
\hline Regional & $85(34.1)$ & $76(34.5)$ & $9(31.0)$ & \\
\hline Combined & $22(8.8)$ & $18(8.2)$ & $4(13.8)$ & \\
\hline Intraoperative benzodiazepines, n (\%) & $55(22.1)$ & $50(22.7)$ & $5(17.2)$ & 0.637 \\
\hline Intraoperative anticholinergics, n (\%) & $143(57.4)$ & $128(58.2)$ & $15(51.7)$ & 0.552 \\
\hline Intraoperative hypotension, n (\%) & $127(51.0)$ & $108(49.1)$ & $19(65.5)$ & 0.115 \\
\hline Intraoperative hypoxemia, n (\%) & $0(0)$ & $0(0)$ & $0(0)$ & - \\
\hline Intraoperative blood loss (mL), median (IQR) & $50(20-200)$ & $50(20-175)$ & $100(30-250)$ & 0.143 \\
\hline Intraoperative blood transfusion, n (\%) & $19(7.6)$ & $15(6.8)$ & $4(13.8)$ & 0.252 \\
\hline Postoperative pain intensity ${ }^{\mathrm{a}}, \mathrm{n}(\%)$ & & & & 0.142 \\
\hline No pain & $32(12.9)$ & $28(12.7)$ & $4(13.8)$ & \\
\hline Mild pain (NRS = 1-3) & 96 (38.6) & $88(40.0)$ & $8(27.6)$ & \\
\hline Moderate pain (NRS = 4-6) & $86(34.5)$ & $77(35.0)$ & $9(31.0)$ & \\
\hline Severe pain (NRS = 7-10) & $35(14.1)$ & $27(12.3)$ & $8(27.6)$ & \\
\hline \multicolumn{5}{|l|}{ Abnormal laboratory values, n (\%) } \\
\hline Preoperative hematocrit < 30\% & $35(14.1)$ & $27(12.3)$ & $8(27.6)$ & 0.042 \\
\hline $\begin{array}{l}\text { Preoperative sodium } \\
<135 \text { or }>145 \mathrm{mEq} / \mathrm{L}\end{array}$ & $24(9.6)$ & $20(9.1)$ & $4(13.8)$ & 0.498 \\
\hline Preoperative BUN/Cr ratio > 20 & $62(24.9)$ & $53(24.1)$ & $9(31.0)$ & 0.493 \\
\hline Length of stay (days), median (IQR) & $7(2-76)$ & $6(2-76)$ & $10(3-36)$ & $<0.001$ \\
\hline Length of stay > 7 days, $\mathrm{n}(\%)$ & $103(41.4)$ & $78(35.5)$ & $25(86.2)$ & $<0.001$ \\
\hline
\end{tabular}

A $p$-value $<0.05$ indicates statistical significance

Abbreviations: $S D$ standard deviation, IQR interquartile range, $B U N / C r$ blood urea nitrogen/creatinine

${ }^{a}$ Maximum pain score using numeric rating scale (NRS) was measured on the first postoperative day

assessment, experience of the investigator, surgery type, and diagnostic tools to assess for delirium. Management goals for reducing the incidence and duration of POD should be included in the clinical guidelines or protocols.

Regarding onset time of POD, most patients in this study (61.3\%) developed POD on postoperative day 1, whereas those in previous studies [22, 23] developed POD on postoperative day 2. However, a POD episode can occur any time during the entire postoperative period. According to the American Geriatrics Society Expert Panel, the clinical guideline for POD recommends that delirium assessment should be performed at least once daily in all patients at high risk for developing delirium [24, 25].

In the present study, pre-existing dementia was the strongest risk factor for POD, with an adjusted risk ratio of 3.95 (95\% CI: 1.91-8.17). This finding is consistent with previous studies $[6,8,26]$ that reported pre-existing dementia as a risk factor for the development of POD. A recent study of non-surgical patients also reported preexisting dementia to be the main risk factor for delirium [27]. Delirium superimposed on dementia (DSD) is the term used for delirium that occurs in patients with preexisting dementia [28]. The prevalence of DSD was reported to be as high as 22-89\% in hospital and 
Table 3 Univariate and multivariate analysis for variables significantly associated with postoperative delirium

\begin{tabular}{|c|c|c|c|c|c|c|}
\hline Variables & $\mathrm{n}$ & Delirium $(n=29)$ & Crude RR (95\% Cl) & $p$-value & Adjusted RR (95\% Cl) & $p$-value \\
\hline \multicolumn{7}{|c|}{ Pre-existing dementia, n (\%) } \\
\hline No & 207 & $13(6.3)$ & 1 & & 1 & \\
\hline Yes & 42 & $16(38.1)$ & $6.07(3.16-11.65)$ & $<0.001$ & $3.95(1.91-8.17)$ & $<0.001$ \\
\hline \multicolumn{7}{|c|}{ Age $\geq 75$ years, $n(\%)$} \\
\hline No & 124 & $6(4.8)$ & 1 & & 1 & \\
\hline Yes & 125 & $23(18.4)$ & $3.80(1.60-9.03)$ & 0.001 & $2.54(1.11-5.80)$ & 0.027 \\
\hline \multicolumn{7}{|c|}{ Preoperative hematocrit <30\%, n (\%) } \\
\hline No & 214 & $21(9.8)$ & 1 & & 1 & \\
\hline Yes & 35 & $8(22.9)$ & $2.33(1.12-4.84)$ & 0.042 & $1.53(0.79-2.96)$ & 0.204 \\
\hline \multicolumn{7}{|c|}{ Preoperative opioids, n (\%) } \\
\hline No & 213 & $18(8.5)$ & 1 & & 1 & \\
\hline Yes & 36 & $11(30.6)$ & $3.62(1.87-7.01)$ & 0.001 & $1.80(0.83-3.91)$ & 0.139 \\
\hline \multicolumn{7}{|c|}{ Preoperative benzodiazepines, n (\%) } \\
\hline No & 212 & $20(9.4)$ & 1 & & 1 & \\
\hline Yes & 37 & $9(24.3)$ & $2.58(1.27-5.22)$ & 0.022 & $1.41(0.66-3.01)$ & 0.370 \\
\hline \multicolumn{7}{|c|}{ Preoperative infection, n (\%) } \\
\hline No & 225 & $23(10.2)$ & 1 & & 1 & \\
\hline Yes & 24 & $6(25.0)$ & $2.45(1.11-5.41)$ & 0.044 & $1.47(0.68-3.19)$ & 0.329 \\
\hline \multicolumn{7}{|c|}{ Barthel Index score $\leq 70, \mathrm{n}(\%)$} \\
\hline No & 198 & $16(8.1)$ & 1 & & 1 & \\
\hline Yes & 51 & $13(25.5)$ & $3.15(1.62-6.13)$ & 0.001 & $1.14(0.54-2.40)$ & 0.734 \\
\hline
\end{tabular}

A $p$-value $<0.05$ indicates statistical significance Abbreviations: $R R$ risk ratio, $C l$ confidence interval

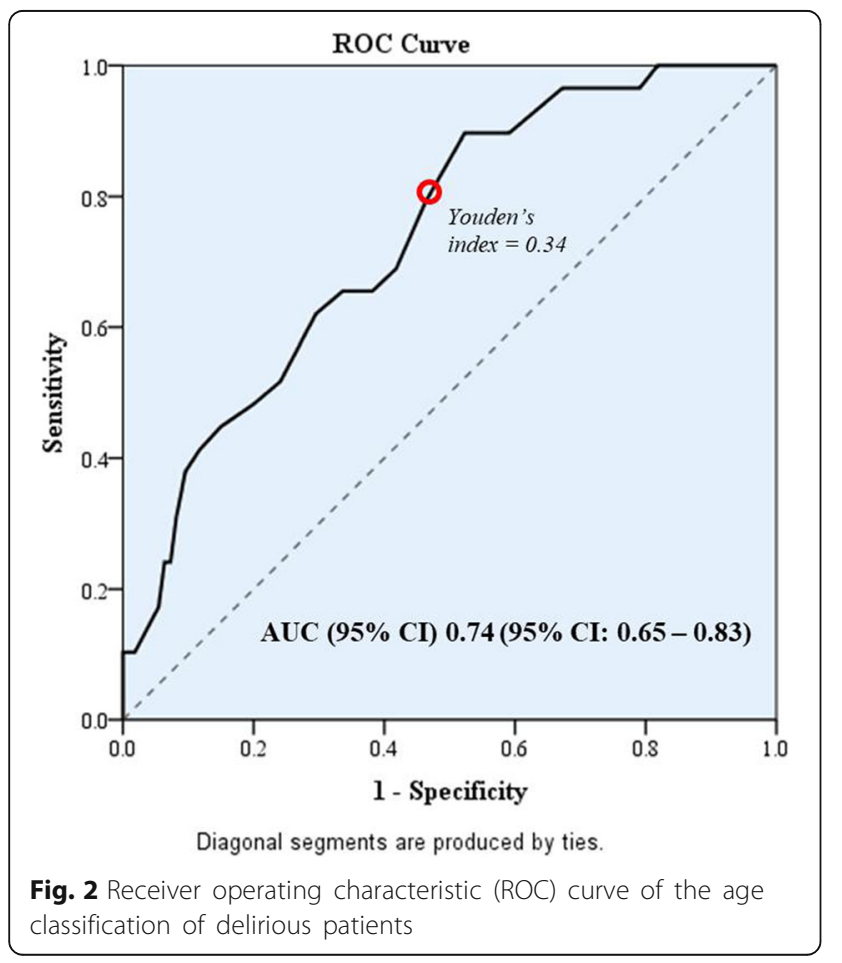

community populations [29], and $1.4-70 \%$ in institutionalized patients [30]. The occurrence of DSD can lead to poor delirium outcomes, including increased risk of mortality, institutionalization, and length of stay [31, 32]. Given the adverse outcomes of delirium, preventive strategies should be implemented to these patients. The delirium prevention strategies include reorientation, hydration, optimized oxygenation, infection control, early mobility, appropriate pain management, medication review, nutrition support, hearing and visual aids, and sleep hygiene [25].

Older age is also an important risk factor for delirium. The present study showed a significant association between POD and age 75 years or older, with an adjusted risk ratio of 2.54 (95\% CI: 1.11-5.80). From previous studies, there were different age groups of patients (e.g., age $\geq 65$, age $\geq 70$, and age $\geq 75$ ) that were identified as groups at high risk for delirium [2, 9, 25]. In the present study, ROC curve analysis revealed age $\geq 75$ years to be the optimal cutoff age for developing delirium, with a sensitivity of $79.3 \%$. This finding suggests that delirium screening might be performed in postoperative noncardiac patients that are aged 75 years or older. Although age is a fixed risk factor that cannot be modified, the delirium prevention and management strategies may be of 
Table 4 Receiver operating characteristic curve analysis of the optimal cutoff age for developing delirium

\begin{tabular}{lllllllll}
\hline Cut point & Sensitivity (\%) & Specificity (\%) & PPV & NPV & LR+ & LR- & $\begin{array}{l}\text { Accuracy } \\
(95 \% \text { Cl) }\end{array}$ & Youden's Index \\
\hline$\geq 65$ & 100.00 & 9.09 & 12.66 & 100.0 & 1.10 & 0.00 & $19.68 \%(14.9-25.2)$ & 0.09 \\
$\geq 70$ & 96.55 & 21.82 & 14.00 & 97.96 & 1.23 & 0.16 & $30.52 \%(24.9-36.6)$ & 0.18 \\
$\geq 75$ & 79.31 & 53.64 & 18.40 & 95.16 & 1.71 & 0.39 & $56.63 \%(50.2-62.9)$ & 0.34 \\
$\geq 80$ & 51.72 & 75.91 & 22.06 & 92.27 & 2.15 & 0.64 & $73.09 \%(67.1-78.5)$ & 0.28 \\
$\geq 85$ & 31.03 & 91.82 & 33.33 & 90.99 & 3.79 & 0.75 & $84.74 \%(79.7-89.0)$ & 0.23 \\
\hline
\end{tabular}

Abbreviations: PPV positive predictive value, NPV negative predictive value, $L R+$ positive likelihood ratio, $L R$ - negative likelihood ratio, $A U C$ area under the curve, 95\% Cl 95\% confidence interval

The optimal cutoff age was age $\geq 75$ years with the best sensitivity and Youden's index

benefit via their effects on intensity and duration of delirium.

Previous studies revealed that delirium may be preventable in $30-40 \%$ of hospitalized older adult patients [33, 34]. Identification of high-risk patients may be helpful in prevention of delirium. The present study demonstrated that patients with pre-existing dementia and age 75 years or older are the most vulnerable high-risk groups. These findings suggest the routine screening for delirium in these groups of patients. Proactive geriatric consultation focusing on these patients may decrease the risk of POD or reduce its severity. Importantly, the involved healthcare professionals should work together as a multidisciplinary team for successful management of POD.

Strengths of the present study include its prospective design, the fact that we used the DSM-5 for diagnosing delirium, and that delirium diagnosis was made by experienced geriatricians. Some limitations must also be mentioned. First, this study was conducted at a single institution. Therefore, our results may not be generalizable to other care settings. Second, the sample size may be too small to identify all significant differences and associations that relate to POD. Third, delirium assessment was only performed once daily, so the incidence of POD may have been underestimated. Finally, some relevant information was not obtained, such as prior postoperative delirium and intraoperative medication usage, and this could have had a confounding effect on our analysis and findings.

\section{Conclusions}

This prospective study found an $11.6 \%$ incidence of postoperative delirium among patients undergoing noncardiac surgery. Pre-existing dementia and age 75 years or older were found to be the independent risk factors for development of POD. Collaborative approach to identify patients at risk for delirium and provide perioperative management strategies may help to prevent POD or reduce its severity. Further studies that focus on multidisciplinary collaboration are needed to improve delirium care.

\section{Abbreviations}

95\% Cl: 95\% confidence interval; ASA: American Society of Anesthesiologists; AUC: Area under the curve; BUN/Cr: Blood urea nitrogen/creatinine; CKD: Chronic kidney disease; DSD: Delirium superimposed on dementia; DSM-5: Diagnostic and Statistical Manual of Mental Disorders Fifth Edition; ESRD: End-stage renal disease; IQCODE: Informant Questionnaire on Cognitive Decline in the Elderly; LR-: Negative likelihood ratio; LR+: Positive likelihood ratio; NPV: Negative predictive value; POD: Postoperative delirium: PPV: Positive predictive value; ROC: Receiver operating characteristic; RR: Risk ratio; TIA: Transient ischemic attack

\section{Acknowledgments}

The authors thank Varalak Srinonprasert and Arunotai Siriussawakul for valuable suggestions; Chulaluk Komoltri and Julaporn Pooliam for help with data analysis; and Puriwat To-adithep, Nipaporn Sangarunakul, and Tashita Pinsanthia for their assistance with patient follow-up and data collection.

\section{Authors' contributions}

Al, OC - study design, literature search, analysis and interpretation of data, drafting of manuscript, critical revision, and approval of final version submitted for publication. TW, PS - study design, literature search, data interpretation, and critical revision. NW, NR - literature search, patient follow-up, data collection, data interpretation, and drafting of manuscript. All authors have read and approved the manuscript in its current state.

\section{Funding}

This study was supported by a grant from the Siriraj Research Development Fund (managed by Routine to Research [R2R]) of the Faculty of Medicine Siriraj Hospital, Mahidol University, Bangkok, Thailand (grant no. R015935052), and a Prasert Prasarttong-Osoth Scholarship from the Medical Association of Thailand, Bangkok, Thailand. The funding bodies have no role in the design of the study and collection, analysis, and interpretation of data and in writing the manuscript.

\section{Availability of data and materials}

The datasets used and/or analyzed during the current study are available from the corresponding author on reasonable request.

The datasets generated and/or analyzed during the present study are not publicly available due to internal institutional restrictions, but they are available from the corresponding author on reasonable request and with the permission of the institution where the data was generated.

Ethics approval and consent to participate

This study was approved by the Siriraj Institutional Review Board of the Faculty of Medicine Siriraj Hospital, Mahidol University, Bangkok, Thailand (COA no. Si 718/2015). After the consent form was approved by the ethics committee, the formal written informed consent from participants was obtained prior to participation in the study. For the participants who were incapable of making and executing the healthcare decisions, the written informed consent was obtained from their spouses or adult children prior to participation. The consenting procedure was approved by the ethics committee.

Consent for publication

Not applicable. 


\section{Competing interests}

The authors declare that they have no competing interests.

\section{Author details}

'Department of Anesthesiology, Faculty of Medicine Siriraj Hospital, Mahidol University, Bangkok 10700, Thailand. ${ }^{2}$ Division of Geriatric Medicine, Department of Medicine, Faculty of Medicine Siriraj Hospital, Mahidol University, Bangkok 10700, Thailand. ${ }^{3}$ Integrated Perioperative Geriatric Excellent Research Center, Faculty of Medicine, Siriraj Hospital, Mahidol University, Bangkok 10700, Thailand.

Received: 26 March 2019 Accepted: 27 January 2020

Published online: 03 February 2020

\section{References}

1. Inouye SK, Westendorp RG, Saczynski JS. Delirium in elderly people. Lancet 2014;383(9920):911-22

2. Dasgupta M, Dumbrell AC. Preoperative risk assessment for delirium after noncardiac surgery: a systematic review. J Am Geriatr Soc. 2006; 54(10):1578-89.

3. American Psychiatric Association. Diagnostic and statistical manual of mental disorders. 5th ed. Arlington: American Psychiatric Association; 2013.

4. Quinlan N, Rudolph JL. Postoperative delirium and functional decline after noncardiac surgery. J Am Geriatr Soc. 2011:59(Suppl 2):S301-4.

5. Hshieh TT, Saczynski J, Gou RY, Marcantonio E, Jones RN, Schmitt E, et al. Trajectory of functional recovery after postoperative delirium in elective surgery. Ann Surg. 2017;265(4):647-53.

6. Sprung J, Roberts RO, Weingarten T, Nunes Cavalcante A, Knopman DS, Petersen $\mathrm{RC}$, et al. Postoperative delirium in elderly patients is associated with subsequent cognitive impairment. Br J Anaesth. 2017;119(2):316-23.

7. Witlox J, Eurelings LS, de Jonghe JF, Kalisvaart KJ, Eikelenboom P, Van Goo WA. Delirium in elderly patients and the risk of postdischarge mortality, institutionalization, and dementia: a meta-analysis. Jama. 2010;304(4):443-51.

8. Robinson TN, Raeburn CD, Tran ZV, Angles EM, Brenner LA, Moss M. Postoperative delirium in the elderly: risk factors and outcomes. Ann Surg. 2009;249(1):173-8

9. Ansaloni L, Catena F, Chattat R, Fortuna D, Franceschi C, Mascitti P, et al. Risk factors and incidence of postoperative delirium in elderly patients after elective and emergency surgery. The Br J Surg. 2010:97(2):273-80.

10. Leslie DL, Marcantonio ER, Zhang Y, Leo-Summers L, Inouye SK. One-year health care costs associated with delirium in the elderly population. Arch Intern Med. 2008;168(1):27-32.

11. Han JH, Zimmerman EE, Cutler N, Schnelle J, Morandi A, Dittus RS, et al. Delirium in older emergency department patients: recognition, risk factors, and psychomotor subtypes. Acad Emerg Med. 2009;16(3):193-200.

12. Ritter SRF, Cardoso AF, Lins MMP, Zoccoli TLV, Freitas MPD, Camargos EF. Underdiagnosis of delirium in the elderly in acute care hospital settings: lessons not learned. Psychogeriatrics. 2018;18(4):268-75.

13. Bellelli G, Nobili A, Annoni G, Morandi A, Djade CD, Meagher DJ, et al. Under-detection of delirium and impact of neurocognitive deficits on inhospital mortality among acute geriatric and medical wards. Eur J Intern Med. 2015;26(9):696-704.

14. Safavynia SA, Arora S, Pryor KO, García PS. An update on postoperative delirium: clinical features, neuropathogenesis, and perioperative management. Curr Anesthesiol Rep. 2018;8(3):252-62.

15. Mahoney FI, Barthel DW. Functional evaluation: the Barthel index. Md State Med J. 1965;14:61-5

16. Siri S, Okanurak K, Chansirikanjana S, Kitiyaporn D, Jorm AF. Modified informant questionnaire on cognitive decline in the elderly (IQCODE) as a screening test for dementia for Thai elderly. Southeast Asian J Trop Med Public Health. 2006:37(3):587-94.

17. Cheung CC, Martyn A, Campbell N, Frost S, Gilbert K, Michota F, et al. Predictors of intraoperative hypotension and bradycardia. Am J Med. 2015; 128(5):532-8.

18. Ehrenfeld JM, Funk LM, Van Schalkwyk J, Merry AF, Sandberg WS, Gawande A. The incidence of hypoxemia during surgery: evidence from two institutions. Can J Anaesth. 2010:57(10):888-97.

19. Bagley SC, White $H$, Golomb BA. Logistic regression in the medical literature: standards for use and reporting, with particular attention to one medical domain. J Clin Epidemiol. 2001;54(10):979-85.
20. Watt J, Tricco AC, Talbot-Hamon C, Rios P, Grudniewicz A, Wong C, et al Identifying older adults at risk of delirium following elective surgery: a systematic review and meta-analysis. J Gen Intern Med. 2018;33:500-9.

21. Chaiwat O, Chanidnuan M, Pancharoen W, Vijitmala K, Danpornprasert $P$, Toadithep $P$, et al. Postoperative delirium in critically ill surgical patients: incidence, risk factors, and predictive scores. BMC Anesthesiol. 2019;19:39.

22. Lynch EP, Lazor MA, Gellis JE, Orav J, Goldman L, Marcantonio ER. The impact of postoperative pain on the development of postoperative delirium. Anesth Analg. 1998;86(4):781-5.

23. Marcantonio ER, Goldman L, Mangione CM, Ludwig LE, Muraca B, Haslauer $\mathrm{CM}$, et al. A clinical prediction rule for delirium after elective noncardiac surgery. Jama. 1994;271(2):134-9.

24. American Geriatrics Society Expert Panel on Postoperative Delirium in Older Adults. Postoperative delirium in older adults: best practice statement from the American Geriatrics Society. J Am Coll Surg. 2015:220(2):136-48 e1.

25. National Institute for Health and Care Excellence (NICE). Delirium: prevention, diagnosis and management. (Clinical guideline 103). London (UK); 2010 [Available from: https://www.nice.org.uk/guidance/cg103. Accessed 1 February 2019.

26. de Castro SM, Ünlü Ç, Tuynman JB, Honig A, van Wagensveld BA, Steller EP et al. Incidence and risk factors of delirium in the elderly general surgical patient. Am J Surg. 2014;208(1):26-32.

27. Gual N, Morandi A, Pérez LM, Brítez L, Burbano P, Man F, et al. Risk factors and outcomes of delirium in older patients admitted to postacute care with and without dementia. Dement Geriatr Cogn Disord. 2018;45(1-2):121-9.

28. Morandi A, Davis D, Bellelli G, Arora RC, Caplan GA, Kamholz B, et al. The diagnosis of delirium superimposed on dementia: an emerging challenge. J Am Med Dir Assoc. 2017;18(1):12-8.

29. Fick DM, Agostini JV, Inouye SK. Delirium superimposed on dementia: a systematic review. J Am Geriatr Soc. 2002;50(10):1723-32.

30. de Lange $E$, Verhaak $P$, van der Meer K. Prevalence, presentation and prognosis of delirium in older people in the population, at home and in long term care: a review. Int J Geriatr Psychiatry. 2013;28(2):127-34.

31. Bellelli G, Frisoni GB, Turco R, Lucchi E, Magnifico F, Trabucchi M. Delirium superimposed on dementia predicts 12-month survival in elderly patients discharged from a postacute rehabilitation facility. J Gerontol A Biol Sci Med Sci. 2007:62(11):1306-9.

32. Jackson TA, Wilson D, Richardson S, Lord JM. Predicting outcome in older hospital patients with delirium: a systematic literature review. Int J Geriatr Psychiatry. 2016;31(4):392-9.

33. Inouye SK, Bogardus ST Jr, Charpentier PA, Leo-Summers L, Acampora D, Holford TR, et al. A multicomponent intervention to prevent delirium in hospitalized older patients. N Engl J Med. 1999;340(9):669-76.

34. Marcantonio ER, Flacker JM, Wright RJ, Resnick NM. Reducing delirium after hip fracture: a randomized trial. J Am Geriatr Soc. 2001;49(5):516-22.

\section{Publisher's Note}

Springer Nature remains neutral with regard to jurisdictional claims in published maps and institutional affiliations.

Ready to submit your research? Choose BMC and benefit from:

- fast, convenient online submission

- thorough peer review by experienced researchers in your field

- rapid publication on acceptance

- support for research data, including large and complex data types

- gold Open Access which fosters wider collaboration and increased citations

- maximum visibility for your research: over $100 \mathrm{M}$ website views per year

At BMC, research is always in progress.

Learn more biomedcentral.com/submissions 